\title{
A visita domiciliar como prática de ensino em odontologia: revisão de literatura
}

\author{
The home visit as a dentistry teaching method: literature review
}

La visita domiciliaria como práctica de enseñanza en odontología: revisión de la literatura

Aline Thomazini Cordeiro ${ }^{1 *}$, Ana Paula Paiva Freitas ${ }^{2}$, Jéssica Aires Saraiva de Oliveira ${ }^{3}$, Marina Lima Sousa Neta ${ }^{4}$, Maynardma Joade M. de Aguiar Souza ${ }^{5}$, Fabiano Maluf

Como citar esse artigo. Cordeiro, AT; Freitas, APP; de Oliviera, JAS; Neta, MLS; Souza, MJMA; Maluf, F. A visita domiciliar como prática de ensino em odontologia: revisão de literatura. Revista Pró-UniverSUS. 2020 Jul./Dez.; 11 (2): $152-157$.

\section{Resumo}

A visita domiciliar (VD), utilizada como prática de ensino, pode contribuir para a formação de um profissional de acordo com o preconizado pelas Diretrizes Curriculares Nacionais (DCN) para o curso de graduação de odontologia. O presente estudo teve por objetivo realizar uma revisão integrativa da literatura com o intuito de reunir e analisar evidências científicas que abordem a experiência e a importância da VD como proposta pedagógica na formação do acadêmico de odontologia. Foi observado que as VD, como metodologia ativa de aprendizagem, contribuem para a formação de um profissional mais humanizado, crítico, criativo e reflexivo, garantindo a integração ensino-serviço-comunidade com a finalidade de aproximar acadêmicos e comunidade, além de assegurar a vivência com outros profissionais da Estratégia Saúde da Família. Entretanto, a literatura ainda aponta algumas limitações, sobretudo a necessidade de uma preparação prévia para o bom desempenho acadêmico da atividade.

Palavras-chave: Visita Domiciliar, Graduação, Odontologia, Estratégia, Ensino.

\begin{abstract}
The home visit (HV), used as a teaching method, can contribute to a professional training according to the requirements recommended by the National Curricular Guidelines (NCG) to the dentistry course. The present study aims to realize an integrative literature review in order to gather and analyze scientific evidences that approach the experience and the importance of the $\mathrm{HV}$ as a pedagogical proposal in the education of dentistry students. It was observed that the $\mathrm{HV}$, as an active learning method, contribute to the formation of a more humanized, critical, creative and reflexive professional, ensuring the teachingservice-community integration for the purpose to bring academics and community together, besides ensuring the experience with other Family Health Strategy professionals. Nevertheless, the literature still points out some limitations, mainly the necessity of a prior preparation for the good academic activity performance.
\end{abstract}

Keywords: Home Visit, Dentistry, Family Health Strategy, Teaching.

\section{Resumen}

La visita domiciliaria (VD), utilizada como práctica de enseñanza, puede contribuir para la formación de un profesional de acuerdo con las exigencias preconizadas por las Directrices Curriculares Nacionales (DCN) para el curso de odontología. El presente estudio tiene el objetivo de realizar una revisión integradora de la literatura con la intención de reunir y analizar evidencias científicas que aborden la experiencia y la importancia de la VD como propuesta pedagógica en la formación del académico de odontología. Se observó que las VD, como metodología activa de aprendizaje, contribuyen para la formación de un profesional más humanizado, crítico, creativo y reflexivo, garantizando la integración enseñanza-servicio-comunidad con la finalidad de acercar académicos y comunidad, además de asegurar la experiencia con otros profesionales de la Estrategia Salud de la Familia. Sin embargo, la literatura aún apunta algunas limitaciones, sobre todo la necesidad de una preparación previa para el buen desempeño académico de la actividad.

Palabras clave: Visita Domiciliaria, Odontología, Estrategia Salud de la Familia, Enseñanza.

Afiliação dos autores:

${ }^{1}$ Acadêmica do curso de Odontologia do Centro Universitário Euroamericano - UNIEURO, Brasília - DF, Brasil. ORCID: https://orcid.org/0000-0002-1153-3924 ${ }^{2}$ Acadêmica do curso de Odontologia do Centro Universitário Euroamericano - UNIEURO, Brasília - DF, Brasil. ORCID: https://orcid.org/0000-0003-3504-1462

${ }^{3}$ Acadêmica do curso de Odontologia do Centro Universitário Euroamericano - UNIEURO, Brasília - DF, Brasil. ORCID: https://orcid.org/0000-0001-6695-1202

${ }^{4}$ Acadêmica do curso de Odontologia do Centro Universitário Euroamericano - UNIEURO, Brasília - DF, Brasil. ORCID: https://orcid.org/0000-0003-1977-6055

${ }^{5}$ Acadêmica do curso de Odontologia do Centro Universitário Euroamericano - UNIEURO, Brasília - DF, Brasil. ORCID: https://orcid.org/0000-0003-2967-6648

${ }^{6}$ Docente do curso de Odontologia do Centro Universitário Euroamericano - UNIEURO, Brasília - DF, Brasil. ORCID: https://orcid.org/0000-0002-3395-069X 


\section{Introdução}

As Diretrizes Curriculares Nacionais (DCN) do curso de graduação em Odontologia têm dentre seus objetivos promover a integração ensino-serviçocomunidade e, com isso, incentivar a aproximação entre acadêmicos e comunidade tendo como base os princípios do Sistema Único de Saúde (SUS) ${ }^{1-3}$.

Para estimular a implantação dessas diretrizes, os Ministérios da Saúde e da Educação criaram políticas de inclusão que integram o ensino-serviço ${ }^{4}$ como, por exemplo, o Programa Nacional de Reorientação da Formação Profissional em Saúde (PRÓ-SAÚDE) e o Programa de Educação pelo Trabalho para a Saúde (PET-SAÚDE) $^{5}$. Esses programas promovem uma formação a fim de atender as necessidades da população, sendo capaz de estreitar o vínculo entre as instituições de ensino e os serviços de saúde ${ }^{6}$.

Desde a institucionalização do SUS, foi estabelecida uma mudança no modelo de saúde até então vigente, visto que sua assistência era curativista, individualizada e com foco na doença (modelo flexeneriano $)^{4,5,7,8}$. Nesse sentido, no ano de 1994, surge a Estratégia Saúde da Família (ESF), com o objetivo de enfatizar a prevenção e a promoção da saúde, e garantir a entrada do cidadão no sistema a partir da atenção primária ${ }^{8}$. Por meio desse modelo, é colocado em prática o cuidado familiar mediante um território adscrito, exercido por uma equipe multiprofissional que irá auxiliar na resolução dos problemas presentes na população $0^{4,9}$.

Diante desse contexto, a visita domiciliar (VD), desenvolvida pelas equipes da ESF, é um importante instrumento que coloca em prática a longitudinalidade do cuidado, a territorialização e o cuidado centrado na pessoa $^{7}$. Segundo Silva ${ }^{8}$, a VD permite a construção de conhecimentos a partir dos problemas reais encontrados e propicia aos estudantes uma formação humanística mais voltada à atuação no SUS. A atenção integral a saúde, educação permanente e a aproximação biopsicossocial, são eixos fundamentais desse processo, cumprindo assim com as competências estabelecias pelas DCN para os cursos da área da saúde $e^{6,8,10}$.

É importante enfatizar o papel que o cirurgiãodentista desempenha na ESF: realizar diagnóstico, instituir tratamento, reabilitação e manutenção em saúde bucal, participar de ações coletivas, prestar serviços de urgência, procedimentos clínicos e cirúrgicos, bem como encaminhar pacientes a outros níveis de atenção de acordo com cada necessidade ${ }^{11}$.

Além disso, tem um papel importante na realização das VD, devido a sua postura ativa na prevenção de agravos e promoção a saúde, instrução de higiene oral e de próteses, escovação supervisionada, aplicação tópica de flúor e identificação de lesões orais, prestando valorosa assistência às pessoas restritas ao $\operatorname{lar}^{12}$.
O presente estudo teve como objetivo realizar uma revisão integrativa da literatura, com o intuito de reunir e analisar evidências científicas que abordem a experiência e a importância da visita domiciliar como proposta pedagógica na formação do acadêmico de Odontologia, através da integração ensino-serviçocomunidade.

\section{Método}

Trata-se de uma revisão integrativa da literatura, que por meio de produções científicas analisa criteriosamente a relevância das visitas domiciliares no processo de ensino-aprendizagem. O estudo, do tipo exploratório, aborda qualitativamente os dados, através de uma investigação descritiva.

O processo de elaboração desse estudo se deu em cinco passos: 1) identificação do tema; 2) busca nas bases de dados de acordo com os critérios de inclusão e exclusão estabelecidos; 3) fichamento e análise dos artigos destacando as ideias centrais e um resumo crítico de cada artigo selecionado; 4) discussão dos resultados e; 5) apresentação da revisão integrativa da literatura.

Foram formuladas as seguintes perguntas para a busca dos artigos: as visitas domiciliares são importantes na formação do acadêmico de odontologia? Qual a participação dos alunos nas visitas domiciliares? Que sentido eles atribuem a essa atividade?

A busca dos artigos foi realizada nas bases de dados SciELO (Scientific Eletronic Library Online), LILACS (Literatura Latino - Americana e do Caribe em Ciências da Saúde), Google Acadêmico. Como critérios de inclusão foram buscados estudos entre os anos de 2012-2020, nos idiomas português e inglês, e seguir o foco de pesquisa da interação do aluno nas visitas domiciliares como proposta pedagógica.

A coleta de dados, dividida entre os autores, ocorreu entre maio e junho de 2020. Para a realização dessa busca foi utilizado os operadores booleanos " $A N D$ " e "OR" usados para as combinações dos descritores visita domiciliar AND odontologia, ("home visit" OR "home Family") AND ("odontology" OR "health") em inglês e/ou português de acordo com a base de dados.

\section{Resultados}

Foram encontrados 31 estudos nas três bases de dados escolhidas. Após a leitura dos resumos, oito foram excluídos por não terem a ideia central relacionada às perguntas do estudo. Na etapa seguinte, realizou-se a leitura na íntegra dos 23 artigos e, nessa fase, 13 artigos foram retirados: cinco deles por não tratarem aspectos de visita domiciliar como proposta pedagógica de ensino, dois excluídos por não estarem compreendidos entre os anos 2012-2020 e seis por apresentarem foco contraditório da pesquisa. Desse modo, dez estudos foram selecionados para a discussão 
Figura 1. Fluxograma representativo da metodologia de inclusão dos artigos sobre a relevância das VD na formação acadêmica dos estudantes.
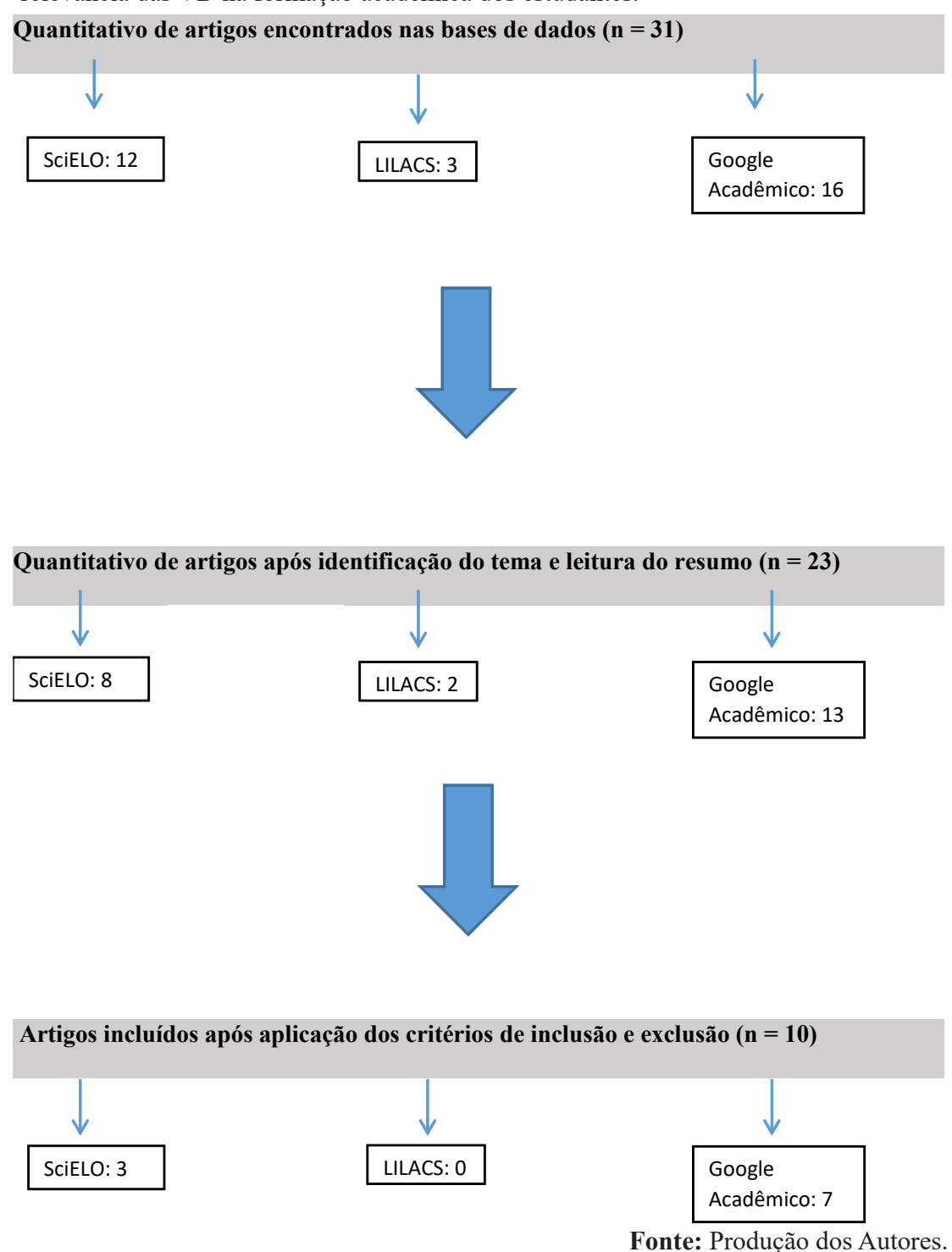

conforme demonstrado na Figura 1.

A Tabela 1 apresenta os dez estudos finais organizados no programa Microsoft Word ${ }^{\circledR}$, com os respectivos itens: título do estudo, a base de dados, o ano de publicação, objetivo, método utilizado e as principais contribuições do estudo.

É oportuno ressaltar que dos dez artigos selecionados, seis estudos foram voltados para ensinoserviço-comunidade, outros dois contaram com a participação de graduandos de outros cursos da saúde não somente da Odontologia, um estudo elencou tanto aspectos positivos quanto os aspectos negativos da VD e apenas um trabalho relata a experiência dos estudantes na participação do programa do PRÓ-PET/SAÚDE.

\section{Discussão}

A Estratégia Saúde da Família, porta de entrada do SUS, tem como objetivo promover uma reorganização da atenção básica, de modo que seu foco esteja voltado para a família promovendo o cuidado de forma individualizada. É possível notar que o processo saúde-doença está intimamente ligado a um conjunto de fatores, não somente a nível biológico, mas também econômico, histórico, cultural e social. Logo, a ESF, exercida de maneira multiprofissional, busca minimizar os problemas recorrentes na comunidade, melhorando a qualidade de vida dos indivíduos, sendo capaz de promover uma relação de vínculo e compreensão da realidade ${ }^{9}$.

É muito importante que todo profissional que trabalhe em contato com o paciente tenha, durante a sua formação, conhecimento de todos os princípios e diretrizes que regem o Sistema Único de Saúde e perceba que ele precisa de profissionais que estejam imbuídos em promover a saúde para os pacientes independente da sua 
Tabela 1. Resultados da revisão integrativa apresentando o título do estudo, objetivo, metodologia e as principais contribuições do estudo.

\begin{tabular}{|c|c|c|c|c|c|}
\hline Título do Artigo & $\begin{array}{c}\text { Base de } \\
\text { Dados }\end{array}$ & Ano & Objetivo & Método & $\begin{array}{c}\begin{array}{c}\text { Principais contribuições } \\
\text { do estudo }\end{array} \\
\end{array}$ \\
\hline $\begin{array}{l}\text { A visita domiciliar como estratégia pedagó- } \\
\text { gica e seus sentidos para estudantes dos cur- } \\
\text { sos de enfermagem, medicina e odontologia } \\
\text { em um Centro Universitário do estado do } \\
\text { Rio de Janeiro. }\end{array}$ & $\begin{array}{c}\text { Google } \\
\text { Acadêmico }\end{array}$ & 2012 & $\begin{array}{l}\text { Analisar o potencial } \\
\text { educativo da VD na } \\
\text { formação em saúde. }\end{array}$ & $\begin{array}{c}\text { Estudo } \\
\text { quantitativo }\end{array}$ & $\begin{array}{l}\text { Conclui que a VD amplia a vi- } \\
\text { são dos acadêmicos quanto à } \\
\text { realidade; favorece a vivência } \\
\text { junto aos usuários e seus con- } \\
\text { textos de vida; proporciona ao } \\
\text { estudante maior experiência } \\
\text { prática. }\end{array}$ \\
\hline $\begin{array}{l}\text { Visitas domiciliares: vivenciando o emprego } \\
\text { das diretrizes curriculares na odontologia, da } \\
\text { teoria a pratica. }\end{array}$ & $\begin{array}{l}\text { Google } \\
\text { Acadêmico }\end{array}$ & 2013 & $\begin{array}{l}\text { Relatar experiências } \\
\text { vivenciadas por aca- } \\
\text { dêmicos do curso de } \\
\text { odontologia. }\end{array}$ & $\begin{array}{l}\text { Relato de } \\
\text { experiência }\end{array}$ & $\begin{array}{l}\text { Relata que a participação dos } \\
\text { estudantes no PRÓ-PET/SAÚ- } \\
\text { DE propicia o desenvolvimen- } \\
\text { to de um profissional gene- } \\
\text { ralista e humanista para atuar } \\
\text { multiprofissionalmente. }\end{array}$ \\
\hline $\begin{array}{l}\text { Impact of family home visits on medical } \\
\text { students' learning in the field of social pe- } \\
\text { diatrics. }\end{array}$ & Scielo & 2013 & $\begin{array}{l}\text { Avaliar o impacto das } \\
\text { VD nos processos de } \\
\text { formação integral. }\end{array}$ & $\begin{array}{l}\text { Estudo } \\
\text { qualitativo }\end{array}$ & $\begin{array}{c}\text { Aborda como as VD influen- } \\
\text { ciam os alunos ao despertar } \\
\text { um olhar mais sensível e hu- } \\
\text { manizado. }\end{array}$ \\
\hline $\begin{array}{l}\text { O significado da participação em visitas do- } \\
\text { miciliares pelo acadêmico de odontologia. }\end{array}$ & Scielo & 2014 & $\begin{array}{l}\text { Identificar o signifi- } \\
\text { cado que os acadê- } \\
\text { micos de odontologia } \\
\text { atribuem às visitas } \\
\text { domiciliares. } \\
\end{array}$ & $\begin{array}{l}\text { Estudo } \\
\text { quantitativo }\end{array}$ & $\begin{array}{l}\text { Apresenta a VD como ativida- } \\
\text { de humanística e o atendimen- } \\
\text { to domiciliar como instrumen- } \\
\text { to que ajuda na resolução de } \\
\text { problemas. } \\
\end{array}$ \\
\hline $\begin{array}{l}\text { Visita domiciliar: estratégia de aproximação } \\
\text { à realidade social? }\end{array}$ & Scielo & 2015 & $\begin{array}{l}\text { Conhecer a percep- } \\
\text { ção dos alunos de } \\
\text { odontologia sobre o } \\
\text { aprendizado na área } \\
\text { da saúde bucal cole- } \\
\text { tiva. } \\
\end{array}$ & $\begin{array}{c}\text { Estudo } \\
\text { quantitativo }\end{array}$ & $\begin{array}{l}\text { Aborda a necessidade das ati- } \\
\text { vidades de VD extrapolarem a } \\
\text { simples coleta de dados relati- } \\
\text { vos ao cadastro dos usuários. }\end{array}$ \\
\hline $\begin{array}{l}\text { Visita domiciliar na formação de estudantes } \\
\text { universitários segundo a política de humani- } \\
\text { zação: análise reflexiva. }\end{array}$ & $\begin{array}{c}\text { Google } \\
\text { Acadêmico }\end{array}$ & 2016 & $\begin{array}{l}\text { Realizar análise re- } \\
\text { flexiva sobre a VD } \\
\text { como estratégia pe- } \\
\text { dagógica. }\end{array}$ & $\begin{array}{l}\text { Revisão de } \\
\text { literatura }\end{array}$ & $\begin{array}{c}\text { Aponta a VD como importante } \\
\text { ferramenta na formação aca- } \\
\text { dêmica ao propiciar uma visão } \\
\text { ampliada e integral do cuidado } \\
\text { e favorecer a assistência hu- } \\
\text { manizada. }\end{array}$ \\
\hline $\begin{array}{l}\text { Ensino sobre visita domiciliar a estudantes } \\
\text { universitários. }\end{array}$ & $\begin{array}{c}\text { Google } \\
\text { Acadêmico }\end{array}$ & 2017 & $\begin{array}{l}\text { Analisar as evidên- } \\
\text { cias científicas da } \\
\text { VD como estratégia } \\
\text { de ensino. }\end{array}$ & $\begin{array}{l}\text { Revisão de } \\
\text { literatura }\end{array}$ & $\begin{array}{c}\text { Retrata a importância da VD } \\
\text { no processo de ensino-apren- } \\
\text { dizagem. }\end{array}$ \\
\hline $\begin{array}{l}\text { A visita domiciliar como prática pedagógica } \\
\text { na formação em odontologia. }\end{array}$ & $\begin{array}{l}\text { Google } \\
\text { Acadêmico }\end{array}$ & 2017 & $\begin{array}{l}\text { Investigar as contri- } \\
\text { buições da VD na } \\
\text { formação odontoló- } \\
\text { gica. } \\
\end{array}$ & $\begin{array}{l}\text { Revisão de } \\
\text { literatura }\end{array}$ & $\begin{array}{c}\text { Demonstra a VD como uma } \\
\text { estratégia pedagógica que be- } \\
\text { neficia o aluno em diversas ha- } \\
\text { bilidades e competências. }\end{array}$ \\
\hline $\begin{array}{c}\text { Visita domiciliar como estratégia de constru- } \\
\text { ção do valor saúde bucal: relato de experiên- } \\
\text { cia de estágio. }\end{array}$ & $\begin{array}{l}\text { Google Aca- } \\
\text { dêmico }\end{array}$ & 2018 & $\begin{array}{l}\text { Apresentar a VD } \\
\text { como uma possibili- } \\
\text { dade de cuidado em } \\
\text { saúde bucal para usu- } \\
\quad \text { ários do SUS. } \\
\end{array}$ & $\begin{array}{l}\text { Relato de } \\
\text { experiência }\end{array}$ & $\begin{array}{l}\text { Demonstra que a VD permite } \\
\text { uma assistência a saúde bucal } \\
\text { do paciente na perspectiva fa- } \\
\text { miliar. }\end{array}$ \\
\hline $\begin{array}{l}\text { Atenção domiciliar em saúde bucal: experi- } \\
\text { ência de integração ensino-serviço-comuni- } \\
\text { dade em centro de saúde da família. }\end{array}$ & $\begin{array}{l}\text { Google } \\
\text { Acadêmico }\end{array}$ & 2019 & $\begin{array}{l}\text { Estabelecer um pro- } \\
\text { tocolo de atenção } \\
\text { domiciliar em saúde } \\
\text { bucal. }\end{array}$ & $\begin{array}{l}\text { Relato de } \\
\text { experiência }\end{array}$ & $\begin{array}{c}\text { Apresenta um protocolo de } \\
\text { integração de ensino-serviço- } \\
\text { comunidade. }\end{array}$ \\
\hline
\end{tabular}

Fonte: Dados do estudo, 2020, 
classe social e motivados a trabalhar em conjunto para melhorar a condição de saúde da população, integrando o serviço à comunidade ${ }^{13}$.

No que se refere a integração ensino-serviçocomunidade, o PRÓ/ PET-SAÚDE, promove a inserção do acadêmico nas atividades realizadas no SUS, com o foco na Atenção Primária à Saúde 4 . Os projetos desenvolvidos por eles têm objetivo de desenvolver competências e habilidades nos alunos de acordo com as diretivas estabelecidas pelas DCN, estimulando a futura inserção dos discentes no Sistema Único de Saúde ${ }^{6}$, promovendo uma aproximação entre as instituições de ensino e o serviço ${ }^{2}$. Nesse contexto de aprendizagem, o estudante é capaz de desenvolver um perfil humanístico, crítico e reflexivo, que permite com que ele atue nos diversos níveis de atenção, tendo em vista sempre a realidade presente da população a ser trabalhada ${ }^{4}$.

A visita domiciliar, considerada como tecnologia leve, tem como objetivo o cuidado voltado para o atendimento tanto educativo quanto assistencial. Promove o estabelecimento de vínculos com a população e traz maior proximidade no contexto social e familiar, e permite um caráter de integralidade e humanização no serviço $^{6}$

De acordo com os estudos analisados, as visitas domiciliares, como estratégia educacional, trazem benefícios aos estudantes não somente para sua vida acadêmica, mas também para sua vida pessoal e atuação profissional. A aproximação biopsicossocial proporcionada pelas VD permite aos estudantes a compreensão das variáveis envolvidas no processo saúde-doença de um indivíduo ou população e também no planejamento das ações de promoção e prevenção na comunidade na área de abrangência ${ }^{2,10,14}$.

A inserção dos estudantes na comunidade por meio das atividades de visitas domiciliares é uma estratégia de ensino ${ }^{4}$ em consonância com as DCN, com os objetivos propostos pelos programas PRÓ/PETSAÚDE e favorece uma aprendizagem vivenciando a realidade para lidar com desafios ${ }^{6}$. Dessa forma, quando bem planejada, a atividade traz benefícios e desperta potencialidades como: humanização, compreensão do processo saúde-doença, atuação na interdisciplinaridade e multiprofissionalidade e um olhar mais sensível para a realidade vivenciada.

A interação dos alunos de odontologia com a comunidade auxilia na sua formação profissional, pois além de aprender os alunos praticam o exercício da cidadania e passam a ter uma visão mais humanista. Ademais, com as visitas domiciliares, os profissionais e alunos conseguem ampliar o diagnóstico e melhorar o plano de tratamento, conhecendo mais a fundo os fatores de proteção e risco presentes no ambiente do indivíduo através do conhecimento do contexto social ${ }^{9,10}$.

Entender o processo saúde-doença é importante para os profissionais de saúde na busca de uma boa qualidade de vida e bem-estar do paciente, mesmo na presença de limitaçoes. E, para que 1sso possa acontecer, é necessário um aprendizado adequado para a formação desses profissionais em busca de uma visão ampliada. A visita domiciliar permite que o aluno tenha competência profissional devido ao maior contato com as famílias e a compreender as expectativas das famílias em relação ao processo saúde-doença ${ }^{2,8}$.

Percebeu-se também que os profissionais da saúde bucal ainda têm dificuldade de trabalhar em equipe ${ }^{15}$. Portanto, a atividade possibitou ao acadêmico de odontologia uma reflexão acerca da importância do trabalho em grupo, melhorando a sua atuação multiprofissional. Nesse sentido, estudo realizado com os alunos de medicina da universidade da Antioquia, Colômbia, revelou aumento na capacidade de aprendizagem e pensamento crítico dos estudantes, ao comparar teoria com realidade, como também de melhorar a habilidade de comunicação, a interdisciplinaridade, o compromisso social, reportando um olhar mais sensível ${ }^{10}$.

Apesar de ser uma importante estratégia de ensino para uma formação humanizada dos futuros cirurgiões-dentistas, ainda são observadas lacunas no seu desenvolvimento, tais como: o precário planejamento da atividade, a falta de discussões após as visitas, a descontinuidade do processo, a falta de conhecimento técnico adequado para a realização das VD e a baixa resolução de problemas dos usuários ${ }^{8}$.

Segundo Borges $^{4}$, o planejamento para a realização da atividade ainda é deficiente, sendo recomendado que haja a prévia organização, o estabelecimento do público alvo e o conhecimento das características epidemiológicas. $\mathrm{O}$ autor relata também a necessidade dos profissionais e estudantes terem acesso aos prontuários dos pacientes com antecedência, respeitando sempre o tempo do atendimento, deixando os pacientes informados acerca do horário da visita e o que se pretende obter por meio desta, evitando possíveis desencontros 4 .

A descontinuidade do processo é outro ponto que pode ser melhorado, pois, na maioria das vezes, as instituições de ensino atribuem como visita domiciliar apenas a coleta de dados para o cadastro na Unidade Básica de Saúde (UBS) ou como prática em estágios nos quais os acadêmicos vão até o domicílio, porém sem continuidade do cuidado. Assim, o tempo se torna artigo raro e, consequentemente, o estudante não consegue criar vínculo com o usuário, sem espaço para diagnóstico, planejamento e execução de procedimentos ${ }^{9,16}$.

Além disso, o elo com a família pode ser dificultado devido aos profissionais e alunos precisarem associar a atividade com a demanda da UBS. É preciso salientar que, as Equipes de Saúde Bucal (ESB) fazem poucas visitas e, quando o fazem, é, na maioria das vezes, por solicitação da família em episódios de dor do paciente restrito ao lar, o que caracteriza um processo de trabalho alienado, pautado em um tratamento clínico 
individual, excludente e tecnicista ${ }^{17}$.

Os estudantes e dentistas também apontam dificuldades na integração com os demais membros que atuam na ESF, o que repercute na falta de discussões após a realização das visitas com consequente postura pouco ativa no cuidado domiciliar, traduzido na baixa resolutividade dos casos encontrados na comunidade ${ }^{18}$. Essa dificuldade de trabalhar em equipe e a pouca realização de visitas domiciliares pelos membros das ESB é presumivelmente devido à sua inserção tardia na $\mathrm{ESF}^{15}$, ampliada com a criação do programa Brasil Sorridente e à dependência de tecnologia ${ }^{1,17}$.

Em estudo realizado por Noro e Torquato ${ }^{9}$, os acadêmicos afirmaram que a atividade auxiliou na compreensão da realidade, porém, outros consideraram a visita domiciliar sem importância para a sua formação, assim como pouca a contribuição para a população vigente, demonstrando uma visão odontocêntrica da formação.

Muitos estudantes se sentem impotentes e frustrados ao realizar as visitas domiciliares, devido a grande maioria estarem no início do curso, afirmando pouca experiência e falta de conhecimento técnico. Dessa forma, é importante o preparo da atividade em relação ao conteúdo teórico e aos possíveis casos que poderão ser encontrados, trabalhando também a habilidade de comunicação para lidar com os pacientes e com o restante da equipe ${ }^{4}$.

Nesse propósito, as visitas domiciliares precisam fazer parte do processo de trabalho da Equipe de Saúde Bucal e dos estudantes, de maneira sistematizada e contínua, com intuito de transpor esse panorama de um olhar curativista e centrado no elemento dental para um olhar vigilante em saúde ${ }^{16}$.

\section{Considerações finais}

Para que o graduando em odontologia possa atuar de acordo com os propósitos das DCN, dos princípios do SUS e dos objetivos da ESF, programas como o PRO/PET-SAÚDE têm auxiliado os alunos a serem mais participativos na atenção básica, por meio da inserção das atividades de visitas domiciliares durante a formação acadêmica.

Desse modo, os estudantes passam a desenvolver um perfil humanístico, crítico, reflexivo e adquirem potencialidades que colaboram para a sua vida acadêmica e atuação profissional. No entanto, algumas limitações ainda persistem, o que requer treinamentos e conhecimentos técnicos para melhor preparação prévia às $\mathrm{VD}$, estreitamento maior do vínculo com os pacientes por meio de uma melhor assiduidade em campo e postura mais ativa no cuidado domiciliar - promovida por discussões entre equipes de saúde bucal, docentes e discentes.

\section{Agradecimento}

Este estudo conta com bolsa do Programa de Iniciação Científica do Centro Universitário Euroamericano - UNIEURO e tem apoio financeiro do Fundo de Amparo à Pesquisa do Distrito Federal (FAPDF).

\section{Referências}

1. Forte FDS, Pontes AA, Morais HGF, Barbosa AS, Sousa Nétto OB. Olhar discente e a formação em Odontologia: interseções possíveis com a Estratégia Saúde da Família. Interface 2019; 23: e170407.

2. Silva RM, Peres ACO, Carcereri DL. A visita domiciliar como prática pedagógica na formação em Odontologia. Rev ABENO 2017; 17(4): 87-98.

3. Brasil. Ministério da Educação. Diretrizes Curriculares Nacionais dos Cursos de Graduação em Farmácia e Odontologia. [Acesso em 20 jun. 2020]. Disponível em: http://portal.mec.gov.br/cne/arquivos/pdf/CES1300.pdf

4. Borges FR, Goyatá SLT, Resck ZMR. Visita Domiciliar na formação de estudantes universitários segundo a Política de Humanização: Análise reflexiva. Rev APS 2016; 19(4): 630-4

5. Farias-Santos BCS, Noro LRA. PET-Saúde como indutor da formação profissional para o Sistema Único de Saúde. Cien Saúde Colet 2017; 22(3): 997-1004.

6. Mecca LE, Jitumori RT, Warkentin PF, Baldani MH, Borges PKO. Visitas domiciliares: vivenciando o emprego das diretrizes curriculares na odontologia, da teoria à prática. Rev ABENO 2013; 13(2): 62-8.

7. Ferraz GA, Leite ICG. Instrumento de visita domiciliar: abordagem da odontologia na estratégia de saúde da família. Rev APS 2016; 19(2): $302-$

8. Silva FAG. A visita domiciliar como estratégia pedagógica e seus sentidos para estudantes dos cursos de Enfermagem, Medicina e Odontologia em um Centro Universitário do Estado do Rio de Janeiro. [Dissertação] - Escola Nacional de Saúde Pública Sergio Arouca, Rio de Janeiro, 2012, 115 f.

9. Noro LRA, Torquato SM. Visita domiciliar: Estratégia de aproximação à realidade social? Trab Educ Saúde 2015; 13(1): 145-57.

10. Cardenas LAG. et al. Impact of family home visits on medical students' learning in the field of social pediatrics. Interface 2013; 17(46): 649-60.

11. Brasil. Ministério da Saúde. Portaria no. 2.436 de 21 de setembro de 2017. Brasília: Diário Oficial da República Federativa do Brasil, 2017.

12. Bizerril DO et al. Papel do cirurgião-dentista nas visitas domiciliares: atenção em saúde bucal. Rev Bras Med Fam Comun 2015; 10(37):1-8.

13. Silva MC, Marques BB, Reis MS, Moraes RB. Pró-Saúde-Odontologia/ UNISC: experiências e contribuições na formação profissional. Rev. ABENO 2011; 11(1): 47-50

14. Batista NM, Rocha ITF, Bonfante GMS. Visita domiciliar como estratégia de construção do valor saúde bucal. Arq Bras Odontol 2019; 14(2): 12-25.

15. Lima PA, Lopes TS Lima AFA, Farias MR, Macial JAC. Atenção Domiciliar em Saúde Bucal: experiência de integração ensino-serviçocomunidade em centro de saúde da família. SANARE, Rev Polit Publ 2019; 18: $90-7$

16. Silva R.M. Atenção à saúde bucal no domicílio no contexto da Estratégia Saúde da Família: reflexões a partir de uma revisão integrativa da literatura. [Monografia]. Universidade Federal de Santa Catarina, Florianópolis, 2016.

17. De-Carli AD, Santos MLM, Souza AS, Kodjaoglanian VL, Batiston AP. Visita domiciliar e cuidado domiciliar na Atenção Básica: um olhar sobre a saúde bucal. Saúde debate 2015; 39(105): 441-50.

18. Deneci V, Medeiros B, Silva D, Vidal K, Chevitarese L. O significado da participação em visitas domiciliares pelo acadêmico de Odontologia. Rev ABENO, 14(1): 66-72, 2014 